\title{
PILOT STUDY OF LOWER UTERINE SEGMENT CESAREAN SCAR THICKNESS PREOPERATIVELY BY TRANSVAGINAL SONOGRAPHY AND ITS CORRELATION WITH INTRA-OPERATIVE FINDINGS
}

\author{
NAVDEEP KAUR ${ }^{1}$, MANJIT MOHI ${ }^{1}$, SARABJIT KAUR ${ }^{1}$, SARYU GUPTA ${ }^{2 *}$ \\ ${ }^{1}$ Department of Obstetrics and Gynaecology, Government Medical College and Rajindra Hospital, Patiala. ${ }^{2}$ Department of Radiodiagnosis,
} Government Medical College and Rajindra Hospital, Patiala. Email: drsaryugupta@gmail.com

Received: 21 June 2021, Revised and Accepted: 01 July 2021

\section{ABSTRACT}

Objectives: Cesarean section rates are increasing with a decrease in the rate of trial of labor after first cesarean section. Proper assessment of uterus especially scar of the previous lower segment cesarean sections (LSCS) in pregnant females is the key stone for the successful vaginal birth after cesarean section. The objective of this pilot study was to evaluate LSCS scar thickness using transvaginal sonography (TVS) and to determine the correlation between TVS and intraoperatively measured lower uterine segment cesarean scar thickness.

Methods: This prospective observational analytic pilot study was carried out jointly by the Departments of Obstetrics and Gynaecology and Radiodiagnosis, Government Medical College and Rajindra Hospital, Patiala after due ethical and research committee approval. 100 women at term with history of previous LSCS and who were scheduled for elective LSCS were recruited for the study after taking the informed consent. Pre-operative scar measurement as on TVS was compared with and analyzed with intraoperative (I/o) scar measurements taken by Calipers.

Results: The cutoff value for TVS readings was found to be $\leq 2.5 \mathrm{~mm}$ using receiver operating characteristic analysis. It has significant correlation with I/o scar measurements. It also has a significant relationship with age, pre-pregnancy overweight, number of the previous LSCS, and gestational age.

Conclusion: Assessment of the scar integrity and quality by TVS will be helpful in selecting candidates for trial of labor with an optimally informed decision but still a number of studies have to be done to develop a robust scoring system.

Keywords: Lower segment caesarean section, Scar thickness, Scar measurements, Transvaginal sonography.

(C) 2021 The Authors. Published by Innovare Academic Sciences Pvt Ltd. This is an open access article under the CC BY license (http://creativecommons.org/ licenses/by/4.0/) DOI: http://dx.doi.org/10.22159/ajpcr.2021v14i9.42491. Journal homepage: https://innovareacademics.in/journals/index.php/ajpcr

\section{INTRODUCTION}

The old dictum "Once a caesarean section, always a caesarean section" has been subjected to critical analysis by the obstetric world. To keep up with the changing world with evidence-based practice, an evidencebased change of policy in favor of vaginal delivery after the previous cesarean section is required.

Studies indicate that the danger of uterine rupture is related with the level of thinning of the Lower uterine segment (LUS) cesarean scar which can be determined by the LUS scar thickness estimation [2]. Various modalities have been utilized to assess the LUS after the lower segment caesarean section (LSCS) such as hysterography of uterine scar, per vaginum investigation of LUS Uterine scar, and amniography but none of them was demonstrated to be valuable in evaluating the risk of uterine rupture. Out of these, ultrasonography (USG) gives a genuinely straightforward and non-invasive method, which has been most widely utilized for assessment of the LUS to evaluate the critical thickness above which safe vaginal birth after cesarian is predictable and safe. Thickness of LUS can be evaluated by either transabdominal sonography (TAS) OR transvaginal sonography (TVS) in the third trimester of pregnancy. Different examinations utilized TVS to contemplate the scar thickness and assessed its value to decide scar thickness in the antenatal period. TVS assessment is an exceptionally precise technique for the recognition of cesarean scar defects, for instance, in relationship with anomalous bleeding or thinning of myometrium, which may expand the risk of uterine rupture [3].

There are not enough studies and literature available on the LUS thickness in Indian population and its comparison with physical nature of scar at the time of repeat cesarean section. In this study, we aimed to correlate the preoperative antenatal USG evaluation of LUS scar and its correlation with intraoperative (I/o) findings.

Aims

- Evaluate LSCS scar thickness using Transvaginal ultrasound antenatally at term

- Determine correlation between TVS and intraoperatively measured LSCS scar thickness.

\section{MATERIALS AND METHODS}

This prospective, observational, and analytic pilot study was carried out in the Departments of Obstetrics and Gynaecology and Radiodiagnosis, Government Medical College and Rajindra Hospital, Patiala after ethical and research committee approval. 100 women at term with history of previous LSCS and who were scheduled for elective LSCS were recruited for the study after taking informed consent. 30 randomly selected full term pregnant females with second or more gravida without the previous LSCS were taken as sample, for determining the baseline measurements. Patient with twin pregnancy, placenta previa, malpresentation, and previous uterine surgery such as myomectomy, polypectomy, and classical cesarean was excluded from the study.

Sample size was calculated using formula $\left(\mathrm{Z}_{1-/ 2}^{\alpha} \mathrm{p}(1-\mathrm{p})\right) / \mathrm{d}^{2}$ where $\mathrm{Z}_{1-/ 2}{ }^{\alpha}$ is Standard normal variate $1.96, \mathrm{~d}$ is absolute error which is taken $7 \%$ in this study, and $\mathrm{p}$ is expected proportion in population which in this study is expected pregnant females with the previous LSCS about 15\%; an estimation based on the previous records who fulfill the inclusion criteria. The calculated sample size was 98 and final sample size was rounded off to 100 patients. 
Table 1: Mean of age, body mass index, period of gestation, and interpregnancy interval in years

\begin{tabular}{|c|c|c|c|c|c|c|c|c|c|c|c|}
\hline Variable & Obs & Total & Mean & Var & Std Dev & Min & $25 \%$ & Median & $75 \%$ & Max & Mode \\
\hline Age in years & 100 & 2770 & 27.7 & 15.04 & 3.88 & 22 & 24 & 28 & 30 & 40 & 28 \\
\hline Body mass index in $\mathrm{Kg} / \mathrm{m}^{2}$ & 100 & 2389.6 & 23.9 & 10.4 & 3.2 & 20 & 22 & 23 & 25.8 & 40 & 24 \\
\hline Period of gestation in weeks & 100 & 3770.2 & 37.70 & 0.82 & 0.90 & 37 & 37 & 37.35 & 38 & 40.7 & 37 \\
\hline Inter pregnancy interval in years & 100 & 390.5 & 3.91 & 3.66 & 1.91 & 1 & 3 & 3 & 5 & 10 & 3 \\
\hline
\end{tabular}

\section{METHODS}

\section{Measurements}

TVS

The thickness of the LUS scar was measured after emptying the bladder. The bladder is identified in the longitudinal plane of the cervical canal. With USG, the LUS appears as a two-layered structure that consists, from the urinary bladder inward, of the echogenic visceral-parietal reflection, including the musculosa and mucosa of the urinary bladder (the outer layer), and the relatively hypoechoic myometrium layer. The vaginal probe was inserted into the vagina with the patient supine, the knees gently flexed, and the hips elevated slightly on a pillow to allow free movement of the operator. With gentle rotation and angulation of the transducer, both sagittal and coronal images could be obtained (Fig. 1). The LUS scar thickness was measured in the sagittal plane and measurements were taken at multiple sites of the LUS and the thinnest portion was considered to be a scar

\section{I/o measurement of LUS cesarean scar}

At the time of surgery, in women who had elective cesarean (not in labor), the LUS was identified as the part of the uterus below the loose reflection of the vesicouterine serosa.

Before the delivery of baby, the thickness of the LUS was measured by the surgeon using a sterile caliper and the thickness of LUS cesarean scar was measured at different sites by placing it after giving the incision over previous uterine scar and rupturing the membranes. Measurement was taken from the inner surface of both the ends of the caliper (Fig. 2). Later on, measurement was taken by putting caliper over scale.

\section{Reference sample for baseline measurements}

30 pregnant females with unscarred uterus admitted in labor room for elective LSCS were taken as reference group after taking due consent to help in estimation of cut off values for scar thickness.

\section{Statistical analysis}

Data collection and analysis were done using Microsoft Excel, Epi info version 7.2.4.0 (CDC Atlanta) and Medcalc Statistical Software. Most of the values are described in percentages and means. While other analytic tests included d' Agostino-Pearson Test and ShapiroWilk Test (For normality of data), Chi-square, Kruskal-Wallis H test, Mann-Whitney test, spearman correlation tes,t and Fisher Exact test. Diagnostic utility parameters such as sensitivity, specificity, Youden index (50\% benchmark for diagnostic utility), positive predictive value (PPV), negative predictive value (NPV), and Kappa were also calculated.

\section{Observations}

The mean age of subjects was $27.7 \pm 3.88$ years with range from 22 to 40 years. Maximum number of participants $54 \%$ was in the age group of 21-25years. The body mass index (BMI) of the study population had a mean of $23.9 \pm 3.3$ (mean \pm SD) with a range of 20-24 at the time of conceiving of current pregnancy (Table 1).

The mean period of gestation was 37.6 weeks of gestation with range of 37-40.7 weeks. $69 \%$ of pregnant women presented at period of gestation between 37 and 38 weeks and rest at $>38$ weeks period of gestation.
Table 2: d' Agostino-Pearson normality test results on study group for reference

\begin{tabular}{lllll}
\hline Variable & Age & Body mass index & POG & Lower uterine segment \\
\hline DA-stat & 4.153 & 5.361 & 3.439 & 2.372 \\
p-value & 0.125 & 0.069 & 0.179 & 0.305 \\
alpha & 0.05 & 0.05 & 0.05 & 0.05 \\
Normal & Yes & Yes & Yes & Yes \\
\hline
\end{tabular}

Mean interval of interpregnancy interval was 3.9 years with a range of $1-10$ years; it was $<3$ years in $19 \%$ cases while $\geq 3$ years was present in $81 \%$ cases.

Maximum number of the previous LSCS 29\% done in study group was due to fetal distress. $15 \%$ of primary LSCS done due to breech in labor, others due to-non progress of labor, cephalopelvic disproportion, Antepartum hemorrhage, Placenta previa, FGR with PPROM, Oligohydramnios, vaginal warts, and Status epilepticus.

\section{Estimation of scar thickness and TVS cut off values}

Reference group for baseline of study

30 randomly selected full term second gravida or more pregnant female with non-scarred uterus for baseline data were tested for normality using d' Agostino-Pearson which showed $p>0.05$ for Age, BMI, POG, and LUS thickness readings (Table 2).

Hence, interpretated as data was sampled from a population that was normally distributed (no difference between the reference data and normal data).

Normal distribution of LUS thickness $=$ mean $\pm 2 \mathrm{SD}=3.35 \pm 2 \times(0.56)$

Hence value of normal range of LUS thickness = Lower limit: $2.23 \mathrm{~mm}$

Upper limit: $4.47 \mathrm{~mm}$

Lower limit of LUS thickness will be considered: $2.23 \mathrm{~mm}$ will be considered cutoff value of Scar thickness in the study. Hence, it can be said that for any scar a thickness of $2.23 \mathrm{~mm}-4.47 \mathrm{~mm}$ would be considered as falling within the normal range (Table 3 ).

Using Scar thickness as $2.23 \mathrm{~mm}$ the TVS cutoff was calculated through receiver operating characteristic Curve analysis using Medcalc Statistical Software (Fig. 3). Cutoff for Scar on TVS thinning was $2.5 \mathrm{~mm}$, that is, any TVS LUS scar reading $\leq 2.5$ was labeled thinned in the study.

From Table $4 \mathrm{a}$ and $\mathrm{b}$, it was evident that optimal cutoff value, that is, with maximum specificity, sensitivity, accuracy, Youden index, and kappa value was $\leq 2.5 \mathrm{~mm}$ group. Kappa was 0.765 which shows substantial agreement.

\section{Distribution of subjects according to measurement cutoffs}

The mean I/o scar measurement was $1.88 \mathrm{~mm}$ with range 0.5 mm- $5 \mathrm{~mm}$ while mean TVS measurement was 2.38 with range $0.8 \mathrm{~mm}$ to $6 \mathrm{~mm}$ About $75 \%$ of the subjects in the study were found to have I/o scar measurement less than the cutoff of $2.23 \mathrm{~mm}$. On the other hand, $65 \%$ of subjects had a measurement $\leq 2.5 \mathrm{~mm}$ which is the cutoff for TVS measurement in this study (Table 5). 
Table 3: Baseline LUS measurements in reference group

\begin{tabular}{|c|c|c|c|c|c|c|c|c|c|c|c|}
\hline Variable & Obs & Total & Mean & Var & Std Dev & Min & $25 \%$ & Median & $75 \%$ & Max & Mode \\
\hline LUS & 30 & 100.5 & 3.35 & 0.31 & 0.56 & 2.5 & 3 & 3.25 & 3.5 & 4.5 & 3 \\
\hline
\end{tabular}

LUS: Lower uterine segment

Table 4a: Receiver operating characteristic curve analysis for TVS cutoff

\begin{tabular}{ll}
\hline Area under the ROC curve (AUC) & \\
Area under the ROC curve (AUC) & 0.966 \\
Standard error & 0.0145 \\
95\% Confidence interval & $0.909-0.992$ \\
z statistic & 32.074 \\
Significance level P (Area=0.5) & $<0.0001$ \\
Youden index & \\
Youden index J & 0.8667 \\
95\% Confidence interval & $0.7733-0.9200$ \\
Associated criterion & $\leq 2.5$ \\
95\% Confidence interval & $\leq 2.1-\leq 3$ \\
Sensitivity & 86.67 \\
Specificity & 100.00 \\
\hline
\end{tabular}

TVS: Transvaginal sonography

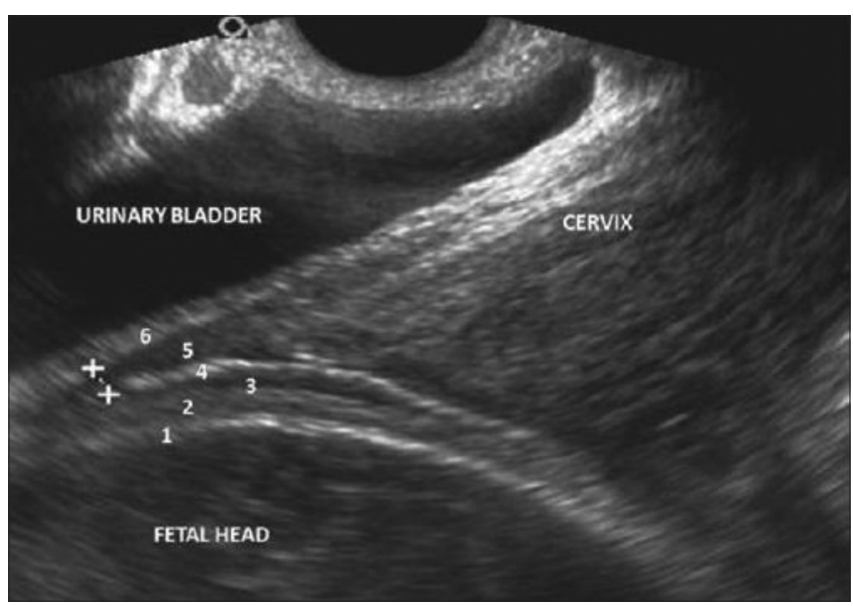

Fig. 1: Normal lower uterine segment juxtaposed to the bladder. The layers seen from the fetal to the maternal side are fetal skull (1) and scalp (2), dark amniotic fluid band (3), hyperechoic decidua and membranes (4), intermediate myometrium (5), and bladder walls (6)

Scar tissue thickness and TVS measurement relationship with various parameters

Age

Table 6a shows mean scar thickness on I/o measurement and on TVS decreased from $2.09 \mathrm{~mm}$ to $1.43 \mathrm{~mm}$ and $2.5 \mathrm{~mm}$ to $1.75 \mathrm{~mm}$, respectively, with increase age from 21 to 25 years to $\geq 31$ years age group which was found to be statistically significant.

Table $6 \mathrm{~b}$ shows a fall in most diagnostic utility parameters except specificity and PPV in 26-30 years age group but remains perfect for $21-25$ years and $\geq 31$ years.

In this study, the thinnest mean scar thickness both intraoperatively and on TVS measurement was found in the $\geq 31$ year's age group.

\section{Overweight}

The mean scar thickness I/o measurement and on TVS among prepregnant women with overweight was less (i.e. $1.77 \mathrm{~mm}$ and $2.20 \mathrm{~mm}$, respectively) than normal weight pre-pregnant women (i.e. $1.92 \mathrm{~mm}$

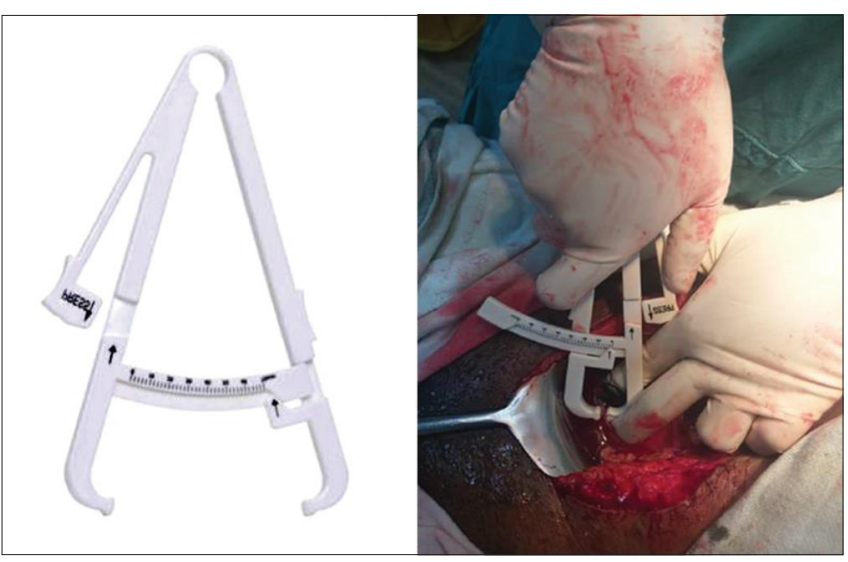

Fig. 2: Caliper used for intraoperative measurements (personal body clip fat measurement tool skinfold test instrument normally used as body fat tester)

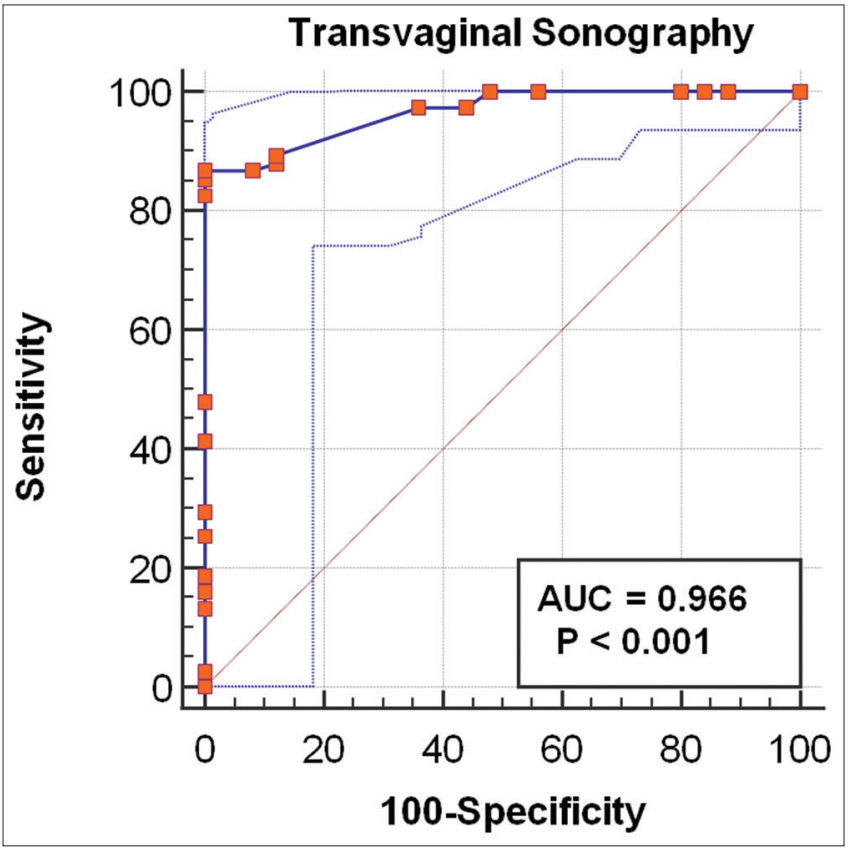

Fig. 3: Receiver operating characteristic curve analysis for transvaginal sonography cutoff

and $2.45 \mathrm{~mm}$, respectively) and the difference was statistically nonsignificant.

Similarly, the diagnostic utility parameters were better in subjects who were not overweight as compared to the overweight ones (Table 7b).

\section{Interpregnancy interval}

The mean scar thickness as measured intraoperatively and on TVS along with diagnostic utility parameters was more in subjects who had an interpregnancy period $<3$ years than those who had $\leq 3$ years (Table $7 \mathrm{a}$ and $\mathrm{b}$ ). 
Table 4b: Values of different diagnostic utility parameters using different TVS cutoffs

\begin{tabular}{|c|c|c|c|c|c|c|c|}
\hline TVS Cut-off & $\leq 1.5$ & $<2$ & $\leq 2$ & $<2.5$ & $\leq 2.5$ & $<3$ & $\leq 3.5$ \\
\hline Sensitivity & $25.33 \%$ & $48.00 \%$ & $82.67 \%$ & $85.33 \%$ & $86.67 \%$ & $89.33 \%$ & $97.33 \%$ \\
\hline Specificity & $100.00 \%$ & $100.00 \%$ & $100.00 \%$ & $100.00 \%$ & $100.00 \%$ & $88.00 \%$ & $64.00 \%$ \\
\hline Positive predictive value & $100.00 \%$ & $100.00 \%$ & $100.00 \%$ & $100.00 \%$ & $100.00 \%$ & $95.71 \%$ & $89.02 \%$ \\
\hline Negative predictive value & $30.86 \%$ & $39.06 \%$ & $65.79 \%$ & $69.44 \%$ & $71.43 \%$ & $73.33 \%$ & $88.89 \%$ \\
\hline Sensitivity + Specificity & 1.253 & 1.480 & 1.827 & 1.853 & 1.867 & 1.773 & 1.613 \\
\hline Accuracy & 0.440 & 0.610 & 0.870 & 0.890 & 0.900 & 0.890 & 0.890 \\
\hline Youden index & 0.253 & 0.480 & 0.827 & 0.853 & 0.867 & 0.773 & 0.613 \\
\hline
\end{tabular}

TVS: Transvaginal sonography

Table 5: Distribution of subjects according to measurement cutoffs

\begin{tabular}{lllll}
\hline Measurements & Cut-off & Frequency & Percent & Exact 95\% LCL \\
\hline intraoperative scar & $<2.23 \mathrm{~mm}$ & 75 & $75.00 \%$ & $65.34 \%$ \\
Transvaginal sonography & $\leq 2.5 \mathrm{~mm}$ & 65 & $65.00 \%$ & $54.82 \%$ \\
Total & & 100 & & $74.12 \%$ \\
\hline
\end{tabular}

Table 6: (a) Mean scar thickness measurement I/o and on TVS of different age groups

\begin{tabular}{|c|c|c|c|c|c|c|c|c|c|c|c|c|c|}
\hline Age groups & Obs & Total & Mean & Var & Std Dev & Min & $25 \%$ & Median & $75 \%$ & Max & Mode & Test & p-value \\
\hline \multicolumn{14}{|c|}{ Scar I/o measurement } \\
\hline 21-25 years & 32 & 67 & 2.09 & 0.81 & 0.90 & 0.5 & 1.5 & 2 & 2.5 & 4 & 2 & Kruskal- & 0.048 \\
\hline $26-30$ years & 54 & 101 & 1.87 & 1.21 & 1.10 & 0.5 & 1 & 2 & 2 & 5 & 2 & Wallis H & \\
\hline$\geq 31$ years & 14 & 20 & 1.43 & 0.65 & 0.81 & 0.5 & 1 & 1 & 2 & 3 & 1 & test & \\
\hline \multicolumn{14}{|c|}{ TVS measurement } \\
\hline 21-25 years & 32 & 80.8 & 2.53 & 1.65 & 1.28 & 1.2 & 1.8 & 2 & 2.85 & 6 & 2 & & 0.028 \\
\hline $26-30$ years & 54 & 132.7 & 2.46 & 1.12 & 1.06 & 0.8 & 1.9 & 2 & 3 & 5.7 & 2 & & \\
\hline
\end{tabular}

Table 6: (b) Diagnostic utility values at different age groups

\begin{tabular}{llll}
\hline Age groups & 21-25 years & 26-30 years & $\mathbf{2 3 1}$ years \\
\hline Sensitivity & $100.00 \%$ & $76.19 \%$ & $100.00 \%$ \\
Specificity & $100.00 \%$ & $100.00 \%$ & $100.00 \%$ \\
Positive predictive value & $100.00 \%$ & $100.00 \%$ & $100.00 \%$ \\
Negative predictive value & $100.00 \%$ & $54.55 \%$ & $100.00 \%$ \\
Sensitivity +Specificity & 2.000 & 1.762 & 2.000 \\
Accuracy & 1 & 0.81 & 1 \\
Youden Index & 1 & 0.76 & 1 \\
Kappa & 1 & 0.59 & 1 \\
\hline
\end{tabular}

Gravida

The mean of measurements of scar intraoperatively and on TVS showed no significant difference between gravida groups. While the diagnostic parameters show better values with three or more gravida than second gravida (Table 8 and 9).

Gestational age

Mean scar thickness significantly increases from 37 to 38 weeks to 38 to 39 weeks and then decreases in $\geq 39$ weeks both in I/o measurements and TVS measurements while the diagnostic parameters decrease from 37 to 38 weeks to 38 to 39 weeks (Table 8 and 9).

\section{Previous lower segment cesarean}

There is significant thinning of LUS if previously more than one LSCS has been done; seen both intraoperatively and on TVS measurement. The diagnostic parameters had $100 \%$ specificity and $100 \%$ sensitivity if previously more than one LSCS had been done (Table 8 and 9).

\section{Correlation of I/o scar measurement with TVS measurement}

In this study with the calculated cutoff both the I/o measurements and TVS measurements were found to be concordant in 90 cases $(90 \%)$;
65 cases were true positive while 25 cases were true negative. 10 cases were discordant - false-negative cases (Table 10).

Scar thickness had a significant relationship with age and number of previous LSCS, both mean measurements decreased with increasing age and number of the previous LSCS.

There was a significant correlation between scar measurements both I/o and TVS with age and number of the previous LSCS besides the two measurement methods themselves (Tables 11 and 12, Figs. 4 and 5).

The scatter diagrams show concentrated red zones of agreement/ concurrence. The cutoff of I/o scar measurement and of TVS shows concentration of readings depicted in the heat map as red zone.

\section{Discordant cases from correlation observation}

On case-to-case analysis of these discordant cases, $6(60 \%)$ were overweight, that is, $23.1 \%$ of the total overweight (26) subjects. The difference of overweight cases measurements by TVS and I/o was found to statistically significant (Fisher exact test, $\mathrm{p}=0.014$ )

The subjects were of the age group 26-30 years (10 subjects), had interpregnancy $\geq 3$ years ( 9 subjects) and had a single previous LSCS. There was a statistically significant difference in measurements of scar by the two methods for these parameters (Fisher exact test, $\mathrm{p}<0.0001$ ).

\section{DISCUSSION}

The present study was a cross-sectional observational study conducted in the Departments of Obstetrics and Gynecology and Radiodiagnosis, Government Medical College and Rajindra Hospital Patiala. The study aimed to assess LUS Thickness using Transvaginal USG and clinical parameters in the previous cesarean section antenatally at term. It also aimed to study the thickness of scar intra operatively at repeat section and to find the association between pre-operative assessment and I/o 

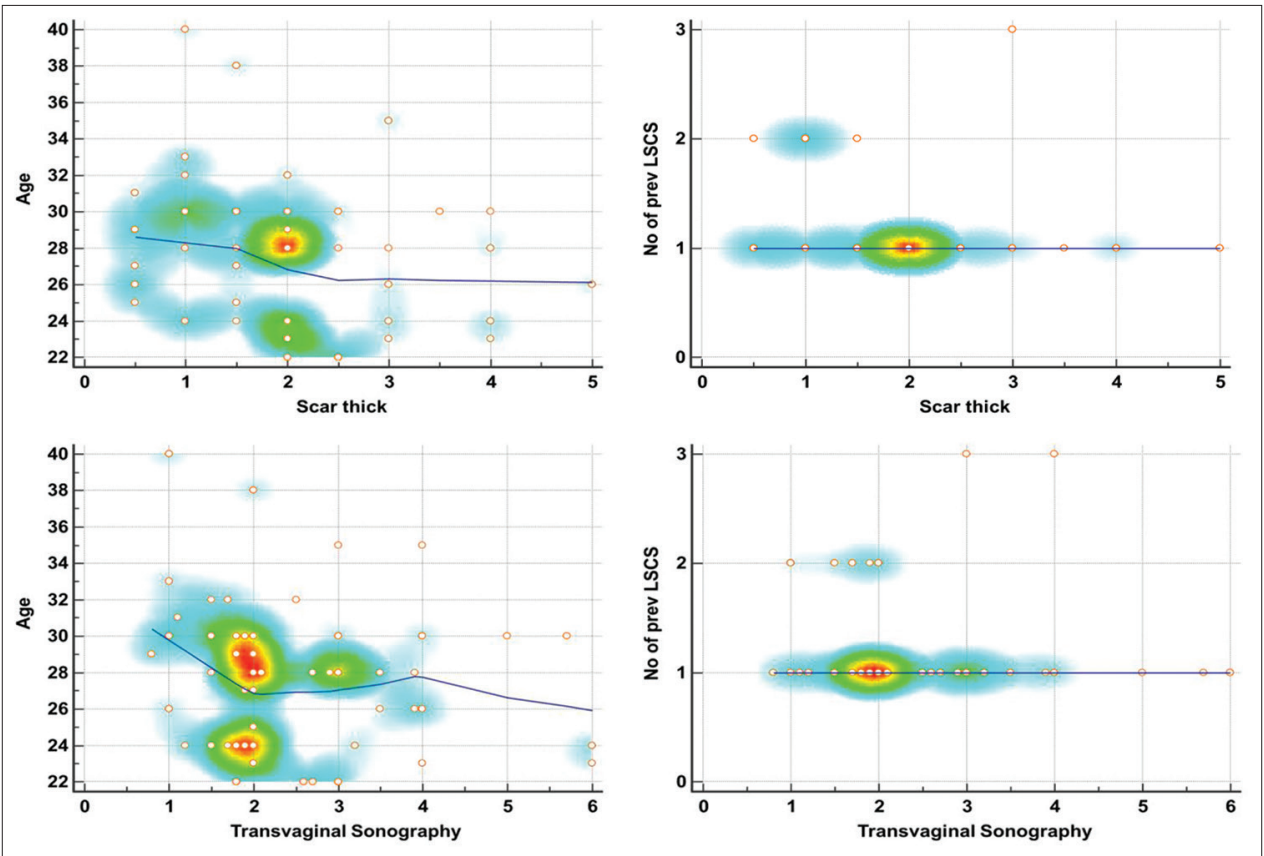

Fig. 4: Scatter diagram with heat map of scar thickness intraoperative* and transvaginal sonography measurement with age and number of the previous lower segment cesarean sections. (*intraoperative scar measurement is labeled scar thick in figure)

Table 7: (a) Mean scar thickness measurement I/o and on TVS of overweight and interpregnancy interval groups

\begin{tabular}{|c|c|c|c|c|c|c|c|c|c|c|c|c|c|}
\hline Overweight & Obs & Total & Mean & Var & Std Dev & Min & $25 \%$ & Median & $75 \%$ & Max & Mode & Test & p-value \\
\hline \multicolumn{12}{|c|}{ Scar I/o measurement } & Mann- & \multirow{3}{*}{0.244} \\
\hline Yes & 26 & 46 & 1.77 & 1.34 & 1.16 & 0.5 & 1 & 1.5 & 2 & 5 & 1 & Whitney & \\
\hline No & 74 & 142 & 1.92 & 0.93 & 0.97 & 0.5 & 1 & 2 & 2.5 & 4 & 2 & test & \\
\hline \multicolumn{14}{|c|}{ TVS measurement } \\
\hline Yes & 26 & 57.1 & 2.20 & 0.98 & 0.99 & 0.8 & 1.5 & 2 & 3 & 4 & 2 & & \multirow[t]{2}{*}{0.466} \\
\hline No & 74 & 181 & 2.45 & 1.39 & 1.18 & 1 & 1.8 & 2 & 3 & 6 & 2 & & \\
\hline \multicolumn{14}{|c|}{ Inter pregnancy Interval } \\
\hline \multicolumn{14}{|c|}{ Scar I/o measurement } \\
\hline$<3$ years & 19 & 40 & 2.11 & 1.96 & 1.40 & 0.5 & 1 & 1.5 & 2.5 & 5 & 1.5 & & \multirow[t]{2}{*}{0.88} \\
\hline$\geq 3$ years & 81 & 148 & 1.83 & 0.82 & 0.91 & 0.5 & 1 & 2 & 2 & 4 & 2 & & \\
\hline \multicolumn{14}{|c|}{ TVS measurement } \\
\hline$<3$ years & 19 & 46.3 & 2.44 & 2.29 & 1.51 & 0.8 & 1.5 & 2 & 3 & 6 & 2 & & \multirow[t]{2}{*}{0.72} \\
\hline$\geq 3$ years & 81 & 191.8 & 2.37 & 1.08 & 1.04 & 1 & 1.8 & 2 & 3 & 6 & 2 & & \\
\hline
\end{tabular}

Table 7: (b) Diagnostic utility values of overweight and interpregnancy interval groups

\begin{tabular}{|c|c|c|c|c|}
\hline \multirow{2}{*}{$\begin{array}{l}\text { Groups and } \\
\text { features }\end{array}$} & \multicolumn{2}{|c|}{ Overweight } & \multicolumn{2}{|c|}{ Interpregnancy interval } \\
\hline & Yes & No & $<3$ years & $\geq 3$ years \\
\hline Sensitivity & $72.73 \%$ & $92.45 \%$ & $92.31 \%$ & $85.48 \%$ \\
\hline Specificity & $100.00 \%$ & $100.00 \%$ & $100.00 \%$ & $100.00 \%$ \\
\hline $\begin{array}{l}\text { Positive } \\
\text { predictive value }\end{array}$ & $100.00 \%$ & $100.00 \%$ & $100.00 \%$ & $100.00 \%$ \\
\hline $\begin{array}{l}\text { Negative } \\
\text { predictive value }\end{array}$ & $40.00 \%$ & $84.00 \%$ & $85.71 \%$ & $67.86 \%$ \\
\hline $\begin{array}{l}\text { Sensitivity } \\
+ \text { Specificity }\end{array}$ & 1.727 & 1.925 & 1.923 & 1.855 \\
\hline Accuracy & 0.77 & 0.95 & 0.95 & 0.89 \\
\hline Youden Index & 0.73 & 0.92 & 0.92 & 0.85 \\
\hline Карра & 0.45 & 0.87 & 0.88 & 0.73 \\
\hline
\end{tabular}

scar evaluation. Before starting the study, permission was taken from the ethical/research committee of the institution.

A total of 100 women with previous LSCS coming to the hospital antenatally at term were recruited for the study. Assessment of LUS cesarean scar using TVS was carried out in all these women followed by assessment of scar thickness intraoperatively done using sterile caliper.

\section{Demographic profile}

The present study observed a mean age of $27.7 \pm 3.88$ years in the study population. Similar mean age was reported by Mangla et al. [5] had 26.7 \pm 3.10 years and Sharma et al. [6] had $27.6 \pm 2.77$ years.

Most of the females, that is, was 54\% were between 26 and 30 years of age group, 32\% were between 21 and 25 years, and $14 \%$ were between 31 and above in the study group.

In the present study, $69 \%$ of women had period of gestation between 37 and 38 and $16 \%$ had between 38 and 39 and $15 \%$ had period of gestation $\geq 39$. The mean period of gestation was 37.6 weeks of gestation. The results were quite similar to 37.7 weeks by weeks Mohammed et al. [2] and <38.4 weeks by Kumari et al. [7]

About $81 \%$ study subjects had $\geq 3$ years of interpregnancy interval with overall mean interval of 3.9 years which was higher than 3.09 years described by Mohammed et al. [2]. 
Table 8: Mean scar thickness measurement I/o and on TVS in gravida, gestational age, and previous lower segment cesarean groups

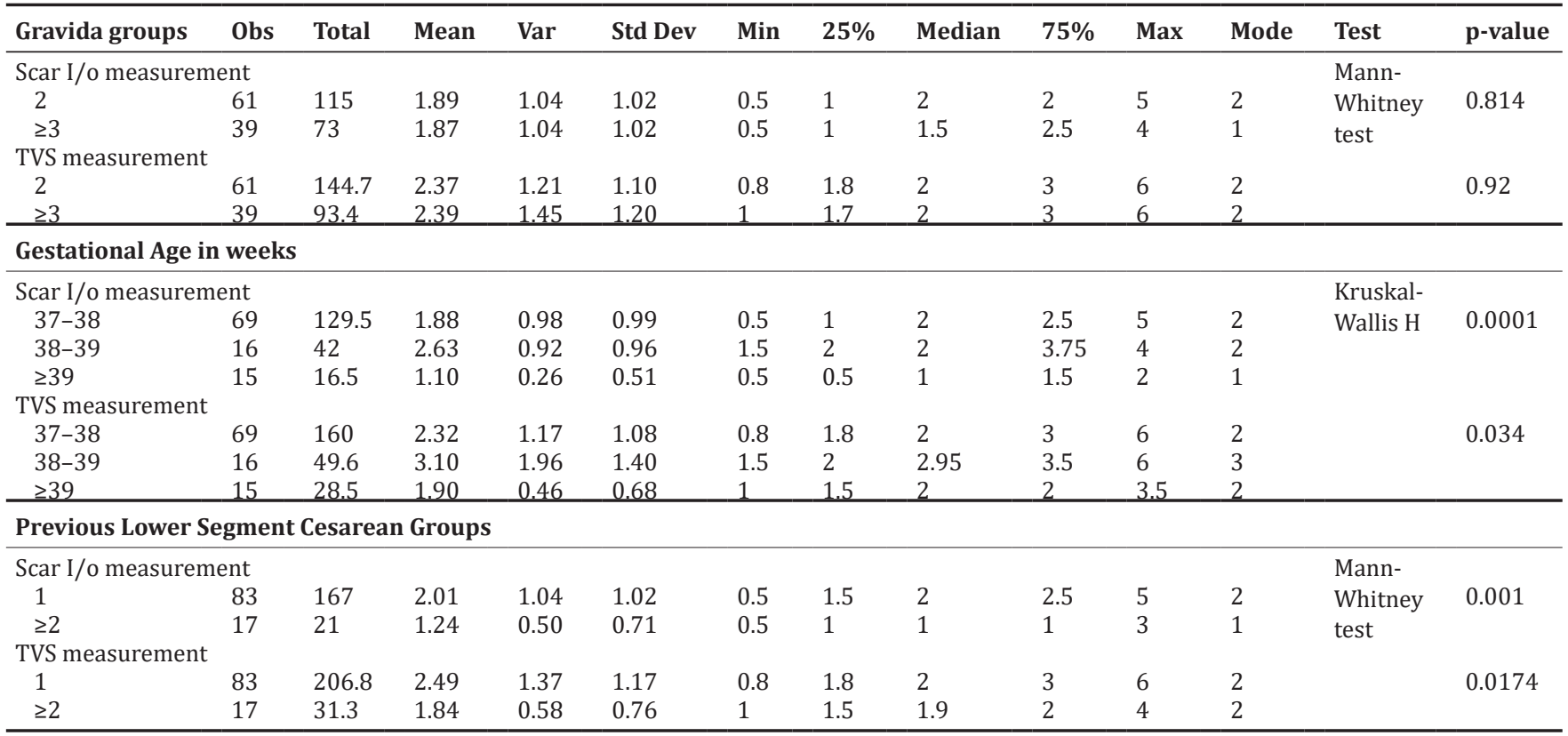

Table 9: Diagnostic utility values of gravida, gestational age, and previous lower segment cesarean groups

\begin{tabular}{|c|c|c|c|c|c|c|}
\hline \multirow[t]{2}{*}{ Groups and features } & \multicolumn{2}{|l|}{ Gravida } & \multicolumn{2}{|c|}{ Gestational age in weeks* } & \multicolumn{2}{|c|}{ Previous lower segment cesarean } \\
\hline & 2 & $\geq 3$ & $37-38$ & 38-39 & 1 & $\geq 2$ \\
\hline Sensitivity & $75.93 \%$ & $88.89 \%$ & $90.20 \%$ & $66.67 \%$ & $83.33 \%$ & $100.00 \%$ \\
\hline Specificity & $100.00 \%$ & $100.00 \%$ & $100.00 \%$ & $100.00 \%$ & $100.00 \%$ & $100.00 \%$ \\
\hline Positive predictive value & $100.00 \%$ & $100.00 \%$ & $100.00 \%$ & $100.00 \%$ & $100.00 \%$ & $100.00 \%$ \\
\hline Negative predictive value & $35.00 \%$ & $80.00 \%$ & $78.26 \%$ & $70.00 \%$ & $69.70 \%$ & $100.00 \%$ \\
\hline Sensitivity +Specificity & 1.759 & 1.889 & 1.902 & 1.667 & 1.833 & 2.000 \\
\hline Accuracy & 0.787 & 0.923 & 0.928 & 0.813 & 0.880 & 1.000 \\
\hline Youden Index & 0.759 & 0.889 & 0.902 & 0.667 & 0.833 & 1.000 \\
\hline Карра & 0.420 & 0.831 & 0.828 & 0.636 & 0.735 & 1.000 \\
\hline
\end{tabular}

*Values of $\geq 39$ weeks not calculated as all cases had measurements less than cutoff both intraoperatively and TVS

Table 10: Intraoperative and transvaginal scar measurements findings as per cutoffs

\begin{tabular}{|c|c|c|c|c|c|}
\hline \multirow{2}{*}{$\begin{array}{l}\text { Transvaginal } \\
\text { Sonography }\end{array}$} & \multicolumn{3}{|c|}{ Scar Thick Groups } & \multirow[t]{2}{*}{ Test } & \multirow[t]{2}{*}{ p value } \\
\hline & $<2.23$ & $\geq 2.23$ & Total & & \\
\hline$\leq 2.5$ & 65 & 0 & 65 & $\begin{array}{l}\text { Fisher } \\
\text { Exact } \\
\text { test }\end{array}$ & $<0.0001$ \\
\hline Row \% & $100.00 \%$ & $0.00 \%$ & $100.00 \%$ & & \\
\hline Col \% & $86.67 \%$ & $0.00 \%$ & $65.00 \%$ & & \\
\hline$>2.5$ & 10 & 25 & 35 & & \\
\hline Row \% & $28.57 \%$ & $71.43 \%$ & $100.00 \%$ & & \\
\hline Col \% & $13.33 \%$ & $100.00 \%$ & $35.00 \%$ & & \\
\hline Total & 75 & 25 & 100 & & \\
\hline Row \% & $75.00 \%$ & $25.00 \%$ & $100.00 \%$ & & \\
\hline Col \% & $100.00 \%$ & $100.00 \%$ & $100.00 \%$ & & \\
\hline
\end{tabular}

The mean I/o scar measurement was $1.88 \mathrm{~mm}$ and TVS measurement was $2.38 \mathrm{~mm}$ which was between $2.6 \mathrm{~mm}$ by Mohammed et al. [1] and $2.08 \mathrm{~mm}$ by Sharma et al. [6].

\section{Antepartum factors assessed during the study}

Interpregnancy interval in present study

TVS done in patients with interpregnancy interval $<3$ years had a sensitivity of $92 \%$ as compared to $85.4 \%$ in $\geq 3$ years with specificity
Table 11: Spearman's rank correlation test for scar thickness measurements intraoperative and transvaginal sonography with age and number of the previous LSCS

\begin{tabular}{|c|c|c|}
\hline Correlation with & $\begin{array}{l}\text { Age in } \\
\text { years }\end{array}$ & $\begin{array}{l}\text { Number of } \\
\text { previous LSCS }\end{array}$ \\
\hline \multicolumn{3}{|c|}{ Scar thickness intraoperative measurement } \\
\hline $\begin{array}{l}\text { Spearman's coefficient of rank } \\
\text { correlation (rho) }\end{array}$ & -0.302 & -0.313 \\
\hline Significance level & $\mathrm{p}=0.0023$ & $\mathrm{p}=0.0015$ \\
\hline $95 \%$ Confidence interval for rho & $\begin{array}{l}-0.470- \\
-0.112\end{array}$ & $-0.480--0.124$ \\
\hline \multicolumn{3}{|c|}{ Scar thickness transvaginal measurement } \\
\hline $\begin{array}{l}\text { Spearman's coefficient of rank } \\
\text { correlation (rho) }\end{array}$ & -0.217 & -0.223 \\
\hline Significance level & $\mathrm{p}=0.0302$ & $\mathrm{p}=0.0257$ \\
\hline $95 \%$ Confidence interval for rho & $\begin{array}{l}-0.396- \\
-0.0214\end{array}$ & $\begin{array}{l}-0.402- \\
-0.0279\end{array}$ \\
\hline
\end{tabular}

LSCS: Lower segment cesarean sections

of $100 \%$ in both. There was no statistically significant difference in measurement of scar thickness with the two methods in the two groups.

Mohammed et al. [2] found that the risk of scar dehiscence was significantly higher with short inter conception period (ICP) (labeled 
interpregnancy interval in this study) ( $\mathrm{p}=0.003)$; while Shipp et al. [8] found inter-delivery intervals of up to 18 months were associated with increased risk of symptomatic uterine rupture during a trial of labor after cesarean delivery compared with that for longer interdelivery intervals. Stamilio et al. [9] found an interval $<6$ months was associated with increased risk of uterine rupture. Sharma et al. [6] also reported similar association with ICP $<18$ months, with the association approaching significance $(\mathrm{p}=0.062)$. However, Bujold et al. [10] suggested that an ICP shorter than 18 months, but not between 18 and 24 months, should be considered as a risk factor for uterine rupture. All these observations suggest that ICP was a major determinant for offering trail of labor after caesarean (TOLAC) in women with previous one C-Section. Shorter ICP was associated with a higher risk of uterine rupture/dehiscence.

\section{Previous LSCS in present study}

The mean scar thickness measurements were $1.24 \mathrm{~mm}$ and $1.84 \mathrm{~mm}$ intraoperatively and on TVS, respectively, in subjects with more than previous LSCS significantly lower than those with previous 1 LSCS (Table 8). About $17 \%$ of the subjects (17) had more than one LSCS.

A study done by Qureshi et al. [11], eight patients were taken with previous two LSCS. Out of these seven patients taken up for elective caesarean due to thin out scar, one patient kept for TOLAC but it was later taken up for LSCS. 35 patients were taken with previous one LSCS out of these ten patients taken up for elective LSCS due to thin out scar while 25 patients were kept for TOLAC. Out of these only 15 patients had successful vaginal delivery.

Association of pre-operative LUS scar thickness by TVS and I/o measured scar thickness

Study showed that the calculated cut off both the I/o measurements and TVS measurements were found to be concordant in 90 cases (90\%); 65 cases were true positive while 25 cases were true negative. 10 cases were discordant - false-negative cases which was found to be statistically significant (Table 10).

The correlation of scar thickness on TVS with I/o measurement was found to significant as shown in Table 12. Fig. 5 which showed a concentration of values around the cutoff values (Heat map-red zone) and a somewhat linear relationship between the two.

The critical cutoff value for safe LUS thickness measured by TVS observed in the present study was $\leq 2.5 \mathrm{~mm}$. The sensitivity, specificity, PPV, and NPV were $86.67 \%, 100 \%, 100 \%$, and $71.43 \%$, respectively. This observation was similar to those of Mohammed et al. [2] and Sen et al. [12] reported a cutoff value of $2.5 \mathrm{~mm}$ in Egyptian and Indian females with previous LSCS, respectively. In the study conducted by Mohammed et al. [2] sensitivity, specificity, PPV, and NPV 90.9\%, 84\%, $71.4 \%$, and 95.5\%, respectively (using TAS), and 81.8\%, 84\%, 69.2\%, and $91.3 \%$, respectively (using TVS), Kumari and Sahu [7] also reported similar findings of cut off value of $2.5 \mathrm{~mm}$ with sensitivity, specificity, PPV, and NPV 81.3\%, 84\%, 69.2\%, and 91.3\% using TVS in Indian population.

Two systematic reviews have also evaluated the issue of LUS USG thickness. In a review of 12 studies Jastrow et al. [19] found that optimal cut-off value varied from $2.0 \mathrm{~mm}$ to $3.5 \mathrm{~mm}$ for full LUS thickness and from 1.4 to 2.0 for myometrial layer. Kok et al. [20] in a meta-analysis, found that pooled sensitivity and specificity of full LUS thickness for cutoffs between 2.0 and $3.0 \mathrm{~mm}$ were 0.61 (95\% CI, 0.42-0.77) and 0.91 (95\% CI, 0.80-0.96); cutoffs between 3.1 and $5.1 \mathrm{~mm}$ reached a sensitivity and specificity of $0.96(95 \% \mathrm{CI}, 0.89-0.98)$ and $0.63(95 \%$ CI, 0.30-0.87).

On the contrary, in two landmark studies, Cheung [14] and Qureshi et al. [11] reported lower cut offs of $1.5 \mathrm{~mm}$ and $2 \mathrm{~mm}$, respectively. The former reported a sensitivity of $88.9 \%$, a specificity of $59.5 \%$ a PPV of $32.0 \%$, and a NPV of $96.2 \%$ in predicting a paper-thin or dehisced LUS;
Table 12: Spearman's rank correlation test of scar thickness measurements intraoperative with transvaginal sonography

\begin{tabular}{ll}
\hline $\begin{array}{l}\text { Scar thickness intraoperative } \\
\text { measurement correlation with }\end{array}$ & $\begin{array}{l}\text { Transvaginal } \\
\text { sonography }\end{array}$ \\
\hline $\begin{array}{l}\text { Spearman's coefficient of rank } \\
\text { correlation (rho) }\end{array}$ & 0.739 \\
Significance level & $\mathrm{p}<0.0001$ \\
95\% Confidence Interval for rho & $0.635-0.817$ \\
\hline
\end{tabular}

Table 13: Studies reporting cutoff values for scar thickness for allowing TOLAC

\begin{tabular}{|c|c|c|c|c|}
\hline Author of study & $\begin{array}{l}\text { Sample } \\
\text { Size }\end{array}$ & Population & Ultrasonography & $\begin{array}{l}\text { Scar } \\
\text { Thickness } \\
\text { cutoff }\end{array}$ \\
\hline Qureshi et al. [11] & 43 & Japanese & TVS & $2 \mathrm{~mm}$ \\
\hline $\begin{array}{l}\text { Rozenberg } \\
\text { et al. [13] }\end{array}$ & 198 & France & TAS & $3.5 \mathrm{~mm}$ \\
\hline Sen et al. [12] & 71 & India & TAS and TVS & $2.5 \mathrm{~mm}$ \\
\hline Cheung [14] & 102 & New York & TVS & $1.5 \mathrm{~mm}$ \\
\hline $\begin{array}{l}\text { Mohammed } \\
\text { et al. [2] }\end{array}$ & 100 & Egypt & TVS & $2.5 \mathrm{~mm}$ \\
\hline Bujold et al. [10] & 236 & Canada & TVS & $2.3 \mathrm{~mm}$ \\
\hline Kushtagi et al. [15] & 106 & India & TAS & $3 \mathrm{~mm}$ \\
\hline Basic et al. [16] & 108 & Europe & TAS & $3.5 \mathrm{~mm}$ \\
\hline Indira et al. [17] & 81 & India & TAS & $3 \mathrm{~mm}$ \\
\hline $\begin{array}{l}\text { Brahmalakshmy } \\
\text { et al. [18] }\end{array}$ & 96 & India & TAS & $3.2 \mathrm{~mm}$ \\
\hline Sharma et al. [6] & 200 & India & TVS and TAS & $2.08 \mathrm{~mm}$ \\
\hline Kumari and Sahu [7] & 140 & India & TVS & $2.5 \mathrm{~mm}$ \\
\hline Present study & 100 & India & TVS & $2.5 \mathrm{~mm}$ \\
\hline
\end{tabular}

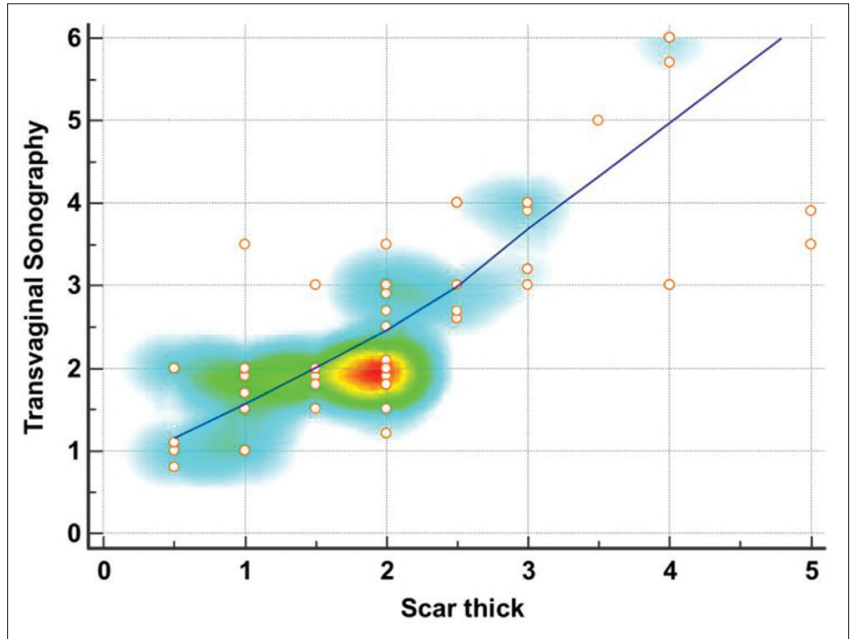

Fig. 5: Scatter diagram with heat map of scar thickness intraoperative* with transvaginal sonography measurement (*intraoperative scar measurement is labeled scar thick in figure)

the latter reported a cut off of $2 \mathrm{~mm}$ using TVS in Japanese population with sensitivity (86.7\%), specificity (100\%), PPV (100\%), and NPV $(86.7 \%)$.

The observations of the present study suggest that the critical cutoff value for safe LUS thickness was $2.5 \mathrm{~mm}$ with good sensitivity and specificity in concordance with most of the Indian studies using TVS (Table 13). The high NPV suggests that a thick LUS was strong and can withstand the stress of labor. Most of the studies show that a strong NPV (86.7-100\%), emphasis that the safety of a trial of vaginal delivery can be predicted with reasonable certainty, when LUS thickness was above the cut off level. 
Certain other features such as pre-pregnancy overweight have to be taken in account of interpretation of TVS measurements as $60 \%$ of the discordant cases in our study were overweight.

The relatively weak PPV suggests that all LUS which are thin on USG are not abnormal; which was similar to results of Rozenberg et al. [13]. This suggests that the prediction of uterine scar dehiscence/rupture was not highly reliable. There was always a component of intra-observer error, which was relatively large for measurements with thin LUS.

\section{CONCLUSION}

The study concludes that the sonographically measured thickness and I/o site thickness of LUS cesarean scar are well correlated to each other. TVS has more sensitivity and specificity for diagnosing the minimum scar thickness of $2.5 \mathrm{~mm}$. TVS is an observer dependent investigation and hence training and competency of the operator has to be ensured for proper interpretation of scan. Existing, for example, gestational age and pre pregnancy conditions such as overweight, age, and number of the previous LSCS have to be kept in mind interpreting TVS measurements before TOLAC. Although assessment of the scar integrity and quality by TVS will be helpful in selecting candidate for trial of labor with an optimally informed decision but still a number of studies have to be done to develop a robust scoring system.

\section{AUTHORS CONTRIBUTION}

Dr. Navdeep Kaur, Senior Resident, contributed in study design and helped in data collection and analysis; Dr Manjit Mohi Ex-head and Professor and Dr Sarabjit Kaur Associate Professor conceptualized the idea, worked on discussions, conclusions, and reviewed manuscript and Dr Saryu Gupta, Associate Professor helped in data collection, analysis and final manuscript preparation.

\section{CONFLICTS OF INTEREST}

Nil.

\section{AUTHORS' FUNDING}

Nil.

\section{REFERENCES}

1. Swift BE, Shah PS, Farine D. Sonographic lower uterine segment thickness after prior cesarean section to predict uterine rupture: A systematic review and meta-analysis. Acta Obstet Gynecol Scand 2019;98:830-41.

2. Mohammed AB, Hamdy MT, Mohammed EM. Ultrasonographic evaluation of lower uterine segment thickness in pregnancy women with previous cesarean section. Middle East Fertil Soc J 2010;15:188-93.

3. Osser OV, Jokubkiene L, Valentin L. High prevalence of defects in cesarean section scars at transvaginal ultrasound examination. Ultrasound Obstet Gynecol 2009;34:90-7.

4. MedCalc ${ }^{\circledR}$. Statistical Software Version 20.006. Ostend, Belgium: MedCalc Software Ltd.; 2021. Available from: https:/www.medcalc. org;2021.

5. Mangla D, Singh SP, Chauhan J. A study to determine scar integrity in pregnant women with previous lower segment caesarean section. Int J Reprod Contracept Obstet Gynecol 2017;5:4.

6. Sharma C, Surya M, Soni A, Soni PK, Verma A, Verma S. Sonographic prediction of scar dehiscence in women with previous cesarean section. J Obstet Gynaecol India 2015;65:97-103.

7. Kumari AS, Sahu S. Transvaginal ultrasonic evaluation of lower uterine segment to predict integrity of caesarean scar during pregnancy and its correlation with obstetric outcome. Indian J Obstet Gynaecol 2015;2:7-10.

8. Shipp TD, Zelop CM, Repke JT, Cohen A, Lieberman E. Interdelivery interval and risk of symptomatic uterine rupture. Obstet Gynecol 2001;97:175-7.

9. Stamilio DM, DeFranco E, Paré E, Odibo AO, Peipert JF, Allsworth JE, et al. Short interpregnancy interval: Risk of uterine rupture and complications of vaginal birth after cesarean delivery. Obstet Gynecol 2007;110:1075-82.

10. Bujold E, Gauthier RJ. Risk of uterine rupture associated with an interdelivery interval between 18 and 24 months. Obstet Gynecol 2010;115:1003-6.

11. Qureshi B, Inafuku $\mathrm{K}$, Oshima $\mathrm{K}$, Masamoto $\mathrm{H}$, Kanazawa $\mathrm{K}$. Ultrasonographic evaluation of lower uterine segment to predict the integrity and quality of cesarean scar during pregnancy: A prospective study. Tohoku J Exp Med 1997;183:55-65.

12. Sen S, Malik S, Salhan S. Ultrasonographic evaluation of lower uterine segment thickness in patients of previous cesarean section. Int J Gynaecol Obstet 2004;87:215-9.

13. Rozenberg P, Goffinet F, Philippe HJ, Nisand I. Thickness of the lower uterine segment: Its influence in the management of patients with previous cesarean sections. Eur J Obstet Gynecol Reprod Biol 1999;87:39-45.

14. Cheung VY. Sonographic measurement of the lower uterine segment thickness: Is it truly predictive of uterine rupture? J Obstet Gynaecol Can 2008;30:148-51

15. Kushtagi P, Garepalli S. Sonographic assessment of lower uterine segment at term in women with previous cesarean delivery. Arch Gynecol Obstet 2011;283:455-9.

16. Basic E, Basic-Cetkovic V, Kozaric H, Rama A. Ultrasound evaluation of uterine scar after cesarean section. Acta Inform Med 2012;20:149-53.

17. Indira KL. Ultrsonographic monitoring of scarred lower uterine segment during pregnancy IOSR J Dent Med Sci 2015;14:56-61.

18. Brahmalakshmy BL, Kushtagi P. Variables influencing the integrity of lower uterine segment in post-cesarean pregnancy. Arch Gynecol Obstet 2015;291:755-62.

19. Jastrow N, Chaillet N, Roberge S, Morency AM, Lacasse Y, Bujold E. Sonographic lower uterine segment thickness and risk of uterine scar defect: A systematic review. J Obstet Gynaecol Can 2010;32:321-7.

20. Kok N, Wiersma IC, Opmeer BC, de Graaf IM, Mol BW, Pajkrt E. Sonographic measurement of lower uterine segment thickness to predict uterine rupture during a trial of labor in women with previous Cesarean section: A meta-analysis. Ultrasound Obstet Gynecol 2013;42:132-9. 